\section{Longevity of Radiofrequency Identification Device Microchips in Citrus Trees}

\author{
Kim D. Bowman \\ US Horticultural Research Laboratory, USDA, ARS, 2001 South Rock Road, \\ Ft. Pierce, FL 34945
}

Additional index words. rootstock improvement, Citrus sinensis, sweet orange, Carrizo
citrange

\begin{abstract}
Long-term identification of individual plants in the field is an important part of many types of research. In a previous report, we described methods for using implanted radiofrequency identification device (RFID) microchips to tag citrus trees for field research. This report provides an update on the RFID technology for use in plants, the effect of implanted chips on long-term plant growth, and survival of the microchips over time. The microchips were found to have no significant effect on plant health and growth, and most microchips continued to work well through the first 6 years after implantation. Implanted RFID microchips appear useful for long-term tagging of citrus and other woody plant species.
\end{abstract}

Labeling of individual plants is a critical component of many types of plant and agricultural research and is essential for success in breeding and development of new crop cultivars (Layne, 1983). Many types of tags have been used for woody tree species, including wood, plastic, metal, and paint, but all have faults that limit their use and useful life. Implantation of radiofrequency identification device (RFID) microchips is widely used for labeling of pets and livestock and in many types of work with wildlife and domestic animals (Buguk et al., 1998; Caceci et al., 1999; Sorenson et al., 1995). The technology is also known as radiofrequency passive integrated transponder tags (Gibbons and Andrews, 2007), and a similar technology based on ultrasound rather than radiofrequency has been developed for aquaculture research (Holm et al., 2007). We previously reported on the use of RFID microchips to label young citrus trees and their potential for long-term identification of woody trees in research (Bowman, 2005). The objective of this study was to evaluate the durability of microchips implanted in citrus trees for 6 years and to assess their potential effect on tree health and growth.

\section{Materials and Methods}

RFID microchip treatments were applied to trees of 'Earlygold' sweet orange (Citrus sinensis) budded onto Carrizo citrange $(C$. sinensis $\times$ Poncirus trifoliata) rootstock in June 2002 as described in the previous report (Bowman, 2005). The treatments were: 1) none; 2) T-cut with no chip insertion; 3) T-cut with insertion of a AVID Code 14-mm glass-

Received for publication 10 Oct. 2008. Accepted for publication 8 Nov. 2008.

e-mailkim.bowman@ars.uda.gov. encased microchip (AVID Microchip I.D Systems, Norco, CA); and 4) T-cut with insertion of ADS 12-mm glass-encased microchip (Applied Digital Solutions, Palm Beach, FL). Experimental trees were maintained in a greenhouse nursery until planting into the field in St. Lucie County, FL, in April $2003, \approx 10$ months after chip insertion. Tree calipers $12 \mathrm{~cm}$ above the graft union and $5 \mathrm{~cm}$ below the graft union were measured at 18 months and 72 months after RFID microchip insertion. A scanner was also used periodically and at each caliper date to verify continued microchip readability. Scanners used for the study were the AVID PowerTracker II for the AVID chip and Destron-Fearing Portable Transceiver System Model 2100 F with a $17.8-\mathrm{cm}$ (7-inch) portable antenna (Destron-Fearing Corp., St. Paul, MN) for the ADS chip. One of the experimental trees was harvested at 72 months to examine the microchip location and appearance of the surrounding plant tissue.

The data for tree growth were tested by analysis of variance using Statistica Version 7.0 (StatSoft, Tulsa, OK).

\section{Results and Discussion}

All the trees used for the implant experiment were generally healthy in appearance throughout the 10 months they were held in the nursery after chip implantation and then the first 62 months in the field (Fig. 1). The $\mathrm{T}$-cut containing the chip generally was completely healed over within 6 months after chip insertion and the tree appeared to grow normally throughout the remainder of the 6 -year observation period. Tree caliper was unaffected by the upright-T cut or implantation of either a $14-\mathrm{mm}$ or $12-\mathrm{mm}$ microchip through the first 72 months (Table 1).

All of the implanted AVID microchips of each type remained readable by scanner (AVID PowerTracker II) through 72 months after implantation. One of the implanted ADS

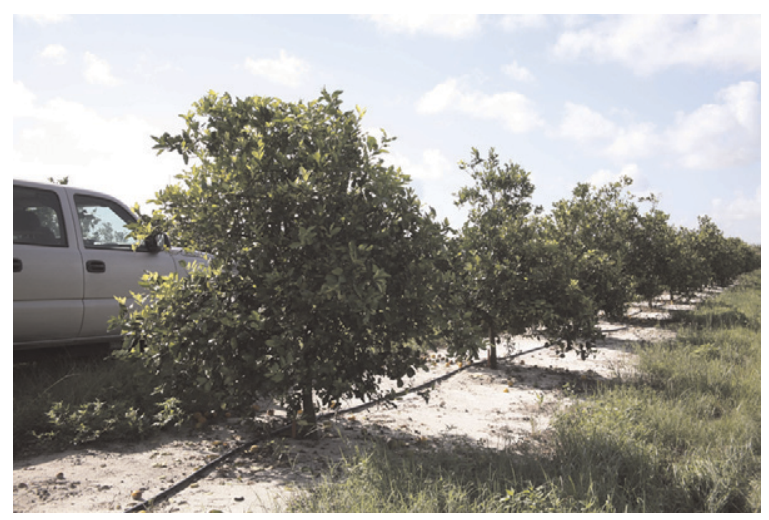

Fig. 1. Experimental sweet orange trees growing for 6 years with radiofrequency identification device microchips inserted into wood just above graft union.

Table 1. Comparison of growth for trees with no treatment (none), a T-cut and no implantation (cut only), and two different sizes of implanted radiofrequency identification device microchips (14-mm and 12$\mathrm{mm}$ diameter).

\begin{tabular}{|c|c|c|c|c|c|c|}
\hline \multirow[b]{3}{*}{ Treatment } & \multicolumn{6}{|c|}{ Caliper of tree $(\mathrm{mm})$} \\
\hline & \multicolumn{3}{|c|}{ Scion (120 $\mathrm{mm}$ above union) } & \multicolumn{3}{|c|}{ Rootstock ( $50 \mathrm{~mm}$ below union) } \\
\hline & Initial & $18 \mathrm{mo.}^{\mathrm{z}}$ & $72 \mathrm{mo}$. & Initial & $18 \mathrm{mo}$. & $72 \mathrm{mo}$. \\
\hline None & 10.14 & 26.97 & 82.61 & 15.82 & 38.77 & 111.27 \\
\hline Cut only & 9.84 & 25.62 & 75.18 & 15.47 & 37.67 & 100.77 \\
\hline AVID $14 \mathrm{~mm}$ & 10.14 & 26.32 & 80.07 & 15.82 & 38.17 & 108.44 \\
\hline ADS 12 mm & 10.03 & 25.23 & 78.37 & 15.71 & 36.12 & 103.34 \\
\hline $\mathrm{SE}$ & 0.34 & 0.80 & 1.99 & 0.38 & 1.42 & 4.12 \\
\hline$P$ value & 0.91 & 0.44 & 0.09 & 0.90 & 0.60 & 0.29 \\
\hline
\end{tabular}

${ }^{\mathrm{z}}$ Months after treatment. 

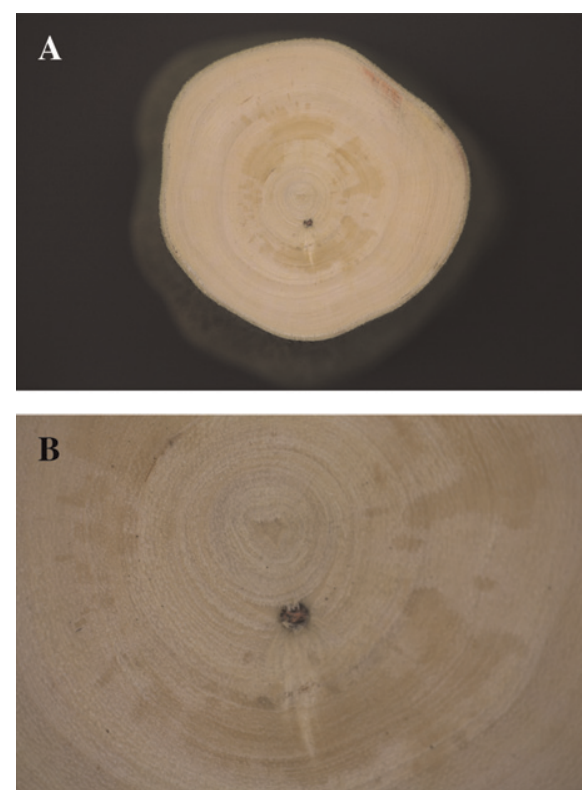

Fig. 2. Cross-section cut through 6-year-old sweet orange tree showing the radiofrequency identification device microchip embedded in wood. (A) Full trunk diameter; (B) closeup of the microchip.

microchips became unreadable (with the Destron-Fearing $2100 \mathrm{~F}$ ) at 50 to 60 months after implantation, and a second became unreadable at 60 to 70 months after implantation. One of the trees with a failed ADS microchip was harvested at 72 months and cross-sectional cuts made to locate and examine the chip (Fig. 2A-B). The microchip was located as expected at 4.5 to $7.0 \mathrm{~cm}$ above the graft union and $\approx 6 \mathrm{~mm}$ from the center of the trunk. There was little necrotic or other abnormal wound tissue associated with the microchip that had been inserted in the wood. The trees with microchips inserted under the bark appeared almost completely unaffected by the insertion or presence of the chips. This was particularly noteworthy because the trees had been exposed to two hurricanes in Sept. 2004 (Category 2 storm Frances and Category 3 storm Jeanne) that caused major limb and trunk damage to neighboring trees, and none of the experimental trees suffered damage to the trunk in the area of the microchip from the strong winds.

It was noted that both chips that failed during the 6-year period of the study were ADS 12-mm chips, whereas none of the AVID 14-mm chips failed. We were not able to determine the cause(s) of the chip failures, but hypothesize that the AVID chip may be more durable, in part, because of its larger size.

RFID microchips appear to have good potential to be used in research where secure long-term tree tags are required. Throughout the 6-year study, at least one type of microchip studied appeared completely reliable in accurately maintaining tree identity. Larger RFID microchips than those used in these studies might be more practical, because they could still easily be inserted into young trees, may be more durable, and might provide a stronger signal and, hence, longer read life as the trunk continues to grow in girth. It should be noted that this microchip trial was planted in 2003 on the USDA Picos Farm in Ft. Pierce, FL, in an area with large commercial acreage in sweet orange and grapefruit production. Between 2005 and 2008, two serious bacterial diseases, citrus bacterial canker (Xanthomonas axonopodis pv. citri) and Huanglongbing (Candidatus Liberibacter asiaticus), have spread into this area and are now beginning to affect many of the experimental trees. Because the scion and rootstock cultivars used for the trial are susceptible to these diseases and there are no known methods to protect the trees from infection or disease progression, it is anticipated that most of the trees in this trial will decline and be lost over the next 5 years.

\section{Literature Cited}

Bowman, K.D. 2005. Secure identification of woody plants with implanted microchips. HortTechnology 15:352-354.

Buguk, C., R.T. Ervin, and J. Eberspacher. 1998 Economic analysis of an alternative cattle identification system used to decrease hide damage. J. Amer. Leather Chemists Assoc. 93:248-254

Caceci, T., S.A. Smith, T.E. Toth, R.B. Duncan, and S.C. Walker. 1999. Identification of individual prawns with implanted microchip transponders. Aquaculture 180:41-51.

Gibbons, J.W. and K.M. Andrews. 2007. PIT tagging: Simple technology at its best. Bioscience 54:447-454.

Holm, S., J. Brungot, A. Ronnekleiv, L. Hoff, V. Jahr, and K.M. Kjolerbakken. 2007. Acoustic passive integrated transponders for fish tagging and identification. Aquacult. Eng. 36:122-126.

Layne, R.E.C. 1983. Hybridization, p. 48-65. In: Moore, J.N. and J. Janick (eds.). Methods in fruit breeding. Purdue Univ. Press, West Lafayette, IN.

Sorenson, M.A., M.S. Buss, and J.W. Tyler. 1995. Accuracy of microchip identification in dogs and cats. J. Amer. Veterninary Medical Assoc. 207:766-767. 